\title{
Pelabelan Harmonis Ganjil pada Graf Bunga Double Quadrilateral
}

\author{
Fery Firmansah ${ }^{1)}$ \\ ${ }^{1)}$ Program Studi Pendidikan Matematika FKIP Universitas Widya Dharma Klaten \\ feryfirmansah@unwidha.ac.id
}

(Article History: Received 16-01-2020; Accepted 09-03-2020; Published 10-03-2020)

\begin{abstract}
ABSTRAK
Graf harmonis ganjil adalah graf yang memenuhi sifat-sifat pelabelan harmonis ganjil. Tujuan dari penelitian ini adalah mendapatkan kelas graf baru yang merupakan graf harmonis ganjil. Metode penelitian yang digunakan terdiri dari beberapa tahapan yaitu konstruksi definisi, formulasi fungsi pelabelan dan pembuktian teorema. Hasil dari penelitian ini adalah konstruksi graf bunga double quadrilateral $F D Q(m)$ dengan $m \geq 1$ dan graf bunga variasi double quadrilateral $F V D Q(m)$ dengan $m \geq 1$ yang merupakan pengembangan dari graf double quadrilateral $D Q$ dan graf variasi double quadrilateral $V D Q$. Lebih lanjut telah dibuktikan bahwa graf $F D Q(m)$ dan $F V D Q(m)$ adalah graf harmonis ganjil.
\end{abstract}

Kata Kunci: graf double quadrilateral, graf bunga, graf harmonis ganjil, pelabelan graf

\section{Odd Harmonious Labelling on The Flower Double Quadrilateral Graphs}

\begin{abstract}
Odd harmonious graphs are graphs that have odd harmonious labeling properties. The purpose of this study is to get a new class of graphs which are odd harmonious graphs. The research method used consists of several stages, namely construction of definitions, formulation of labeling functions and proof of theorems. The results of this study is to get a graph construction will be given, namely the flower quadrilateral graphs $F D Q(m)$ with $m \geq 1$ and the flower variation of quadrilateral graphs $F D Q(m)$ with $m \geq 1$, which are the development of double quadrilateral graphs $D Q$ and variation double quadrilateral graphs $V D Q$. It has further been proven that $F D Q(m)$ and $F V D Q(m)$ are odd harmonious graphs.
\end{abstract}

Keywords: double quadrilateral graph, flower graph, labeling graph, odd harmonious graph

\section{PENDAHULUAN}

Sedlacek memperkenalkan pertama kali teori pelabelan graf pada tahun 1963. Sampai tahun 2019 Gallian telah mengumpulkan banyak hasil penelitian pelabelan graf baik dari sisi pengembangan teori maupun aplikasi dalam berbagai bidang keilmuan. Liang dan Bai pada tahun 2009 memperkenalkan salah satu jenis dari pelabelan graf yang harmonis yaitu pelabelan graf harmonis ganjil (Gallian, 2019).

Pelabelan harmonis ganjil graf $G$ pada dasarnya adalah pemetaan setiap elemen titik ke bilangan bulat positif $\{0,1,2,3, \ldots, 2 q-1\}$ yang bersifat injektif, sedemikian sehingga menginduksi pemetaan setiap elemen garis ke bilangan bulat positif ganjil $\{1,3,5,7, \ldots, 2 q-$ 1 ) yang bersifat bijektif, dengan $f^{*}(c d)=$ $f(c)+f(d)$ dan $q$ order dari graf $G$ (Liang dan Bai, 2009).

Penelitian yang relevan dengan penelitian ini antara lain. Rismayati (2013) membuktikan bahwa graf hairy lingkaran, graf shadow lingkaran dan generalisasi graf shadow lingkaran adalah graf harmonis ganjil. Abdel-Aal (2014) membuktikan bahwa dua graf lingkaran dengan sebuah busur persekutuan adalah graf harmonis ganjil. Firmansah dan Yuwono (2017) membuktikan bahwa kelas graf baru hasil operasi cartesian product adalah graf harmonis ganjil. Pada 
makalah yang berbeda Firmansah dan Yuwono (2017a) juga membuktikan bahwa graf kincir angin belanda berlipat adalah graf harmonis ganjilJeyanthi \& Philo (2019) membuktikan bahwa graf super subdevisi adalah graf harmonis ganjil. Firmansah \& Tasari (2020) membuktikan bahwa amalgamasi garis dari graf double quadrilateral adalah graf harmonis ganjil.

Firmansah \& Syaifuddin (2016) membuktikan bahwa graf kincir angin double quadrilateral $D Q^{(k)}$ adalah graf harmonis ganjil. Selanjutnya Firmansah (2017) memperkenalkan graf variasi double quadrilateral $V D Q$ dan graf kincir angin variasi double quadrilateral $V D Q^{(k)}$, lebih lanjut telah dibuktikan bahwa graf $V D Q^{(k)}$ adalah graf harmonis ganjil. Firmansah \& Syaifuddin (2018) dan Firmansah \& Syaifuddin (2018a) membuktikan bahwa amalgamasi graf kincir angin double quadrilateral $D Q^{(k)} * P_{2} * D Q^{(k)}$ adalah graf harmonis ganjil.

Pada makalah ini peneliti tertarik untuk mengembangkan kelas graf baru yaitu graf bunga double quadrilateral $F D Q(m)$ dan graf bunga variasi double quadrilateral $F V D Q(m)$ yang merupakan pengembangan dari graf $D Q$ dan $V D Q$. Selain itu peneliti juga akan membuktikan bahwa graf bunga double quadrilateral $F D Q(m)$ dan graf bunga variasi double quadrilateral $F V D Q(m)$ adalah graf harmonis ganjil.

\section{METODE PENELITIAN}

Metode penelitian yang telah dikerjakan terdiri dari bebarapa langkah antara lain. (1) Membentuk definisi kelas graf baru beserta gambarnya, (2) memformulasikan fungsi pelabelan titik dan fungsi pelabelan garis dengan sifat-sifat tertentu, dan (3) menyatakan dalam bentuk teorema disertai dengan pembuktian secara matematis.

\section{HASIL DAN PEMBAHASAN}

Berikut diberikan definisi dari graf bunga double quadrilateral $F D Q(m)$ dengan $m \geq 1$ dan graf bunga variasi double quadrilateral $F V D Q(m)$ dengan $m \geq 1$. Selanjutnya diberikan sifat yang menyatakan bahwa graf bunga double quadrilateral $F D Q(m)$ dengan $m \geq 1$ dan graf bunga variasi double quadrilateral $F V D Q(m)$ dengan $m \geq 1$ adalah graf harmonis ganjil.

Definisi 1. Graf bunga double quadrilteral yang dinotasikan dengan $F D Q(m), m \geq 1$ adalah graf yang mempunyai himpunan titik $V(F D Q(m))=\left\{u_{0}\right\} \cup$ $\left\{u_{i} \mid 1 \leq i \leq 2 m+1\right\} \cup$

$\left\{v_{i}^{j} \mid 1 \leq i \leq m, j=1,2\right\}$ dan himpunan garis $E(F V D Q(m))=$ $\left\{u_{0} u_{i} \mid 1 \leq i \leq 2 m+1\right\} \cup$ $\left\{u_{2 i-1} v_{i}^{1} \mid 1 \leq i \leq m, j=1\right\} \cup$ $\left\{v_{i}^{j} u_{2 i} \mid 1 \leq i \leq m, j=1,2\right\} \cup$ $\left\{u_{2 i+1} v_{i}^{2} \mid 1 \leq i \leq m, j=2\right\}$.

Berdasarkan Definisi 1 diperoleh order $p(F D Q(m))=4 m+2 \quad$ dan $\quad$ size $q(F D Q(m))=6 m+1$.

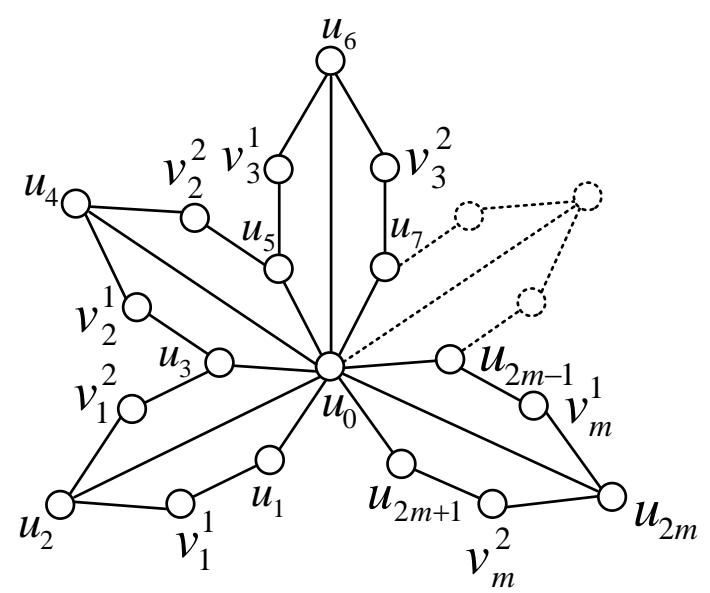

Gambar 1. Konstruksi dan definisi titik dari graf bunga double quadrilateral $F D Q(m)$ dengan $m \geq 1$.

Teorema 2. Graf bunga double quadrilteral $F D Q(m)$ dengan $m \geq 1$ adalah graf harmonis ganjil.

Bukti.

Didefinisikan fungsi pelabelan titik $f: V(F D Q(m)) \rightarrow\{0,1,2,3, \ldots, 12 m+1\}$

$f\left(u_{0}\right)=0$

$f\left(u_{i}\right)=2 i-1,1 \leq i \leq 2 m+1$

$f\left(v_{i}^{j}\right)=12 m-12 i+2 j+4$,

$1 \leq i \leq m, j=1,2$

Berdasarkan persamaan (1), (2), dan (3) diperoleh

$f(V(F D Q(m)))=\{0\} \cup\{1,3,5,7, \ldots, 4 m+$ 1\} $\cup\{12 m-6,12 m-18,12 m-30,12 m-$ 
$42, \ldots, 6,12 m-4,12 m-16,12 m-$

$28,12 m-40, \ldots, 8\}$

$=\{0,1,3,5,6,7,8, \ldots, 4 m+1, \ldots, 12 m-$

$42,12 m-40,12 m-30,12 m-28,12 m-$

$18,12 m-16,12 m-6,12 m-4\}$

$=\{0,1,3,5, \ldots, 12 m-4\}$

Didapatkan himpunan titik setelah diberikan label $\quad f(V(F D Q(m)))=$ $\{0,1,3,5, \ldots, 12 m-4\} \subseteq\{0,1,2,3, \ldots, 12 m+$ 1\}. Disisi yang lain terlihat juga bahwa himpunan titik setelah diberi label $f(V(F D Q(m)))=\{0,1,3,5, \ldots, 12 m-4\}$ menghasilkan label yang berbeda-beda pada setiap titiknya. Sehingga didapatkan fungsi pelabelan titik bersifat injektif.

Didefinisikan fungsi pelabelan garis $f^{*}: E(F D Q(m)) \rightarrow\{1,3,5,7, \ldots, 12 m+1\}$

$f^{*}\left(u_{0} u_{i}\right)=2 i-1,1 \leq i \leq 2 m+1$

$f^{*}\left(u_{2 i-1} v_{i}^{1}\right)=12 m-8 i+2 j+1$,

$1 \leq i \leq m, j=1$

$f^{*}\left(v_{i}^{j} u_{2 i}\right)=12 m-8 i+2 j+3$,

$1 \leq i \leq m, j=1,2$

$f^{*}\left(u_{2 i+1} v_{i}^{2}\right)=12 m-8 i+2 j+5$,

$1 \leq i \leq m, j=2$

Berdasarkan persamaan (4), (5), (6), dan (7) diperoleh

$f^{*}(E(F D Q(m)))=\{1,3,5,7, \ldots, 4 m+1\} \cup$ $\{12 m-5,12 m-13,12 m-21,12 m-$ $29, \ldots, 4 m+3\} \cup\{12 m-3,12 m-$ $11,12 m-19,12 m-27, \ldots, 4 m+5,12 m-$ $1,12 m-9,12 m-17,12 m-25, \ldots, 4 m+$ 7\} $\cup\{12 m+1,12 m-7,12 m-15,12 m-$ $23, \ldots, 4 m+9\}$

$=\{1,3,5,7, \ldots, 4 m+1,4 m+3,4 m+5,4 m+$ $7,4 m+9, \ldots, 12 m-29,12 m-27,12 m-$ $25,12 m-23,12 m-21,12 m-19,12 m-$ $17,12 m-15,12 m-13,12 m-11,12 m-$ $9,12 m-7,12 m-5,12 m-3,12 m-$ $1,12 m+1\}$

$=\{1,3,5,7, \ldots, 12 m+1\}$

Didapatkan himpunan garis setelah diberikan label $f^{*}(E(F D Q(m)))=$ $\{1,3,5,7, \ldots, 12 m+1\}$. Disisi yang lain terlihat juga bahwa himpunan garis setelah diberi label $f^{*}(E(F D Q(m)))=$ $\{1,3,5,7, \ldots, 12 m+1\}$ menghasilkan label yang berbeda-beda pada setiap garisnya.
Sehingga didapatkan fungsi pelabelan garis bersifat bijektif.

Sedemikian sehingga diperoleh graf bunga double quadrilateral $F D Q(m)$ dengan $m \geq 1$ adalah graf harmonis ganjil.

Contoh 3. Pelabelan harmonis ganjil pada graf $F D Q(5)$

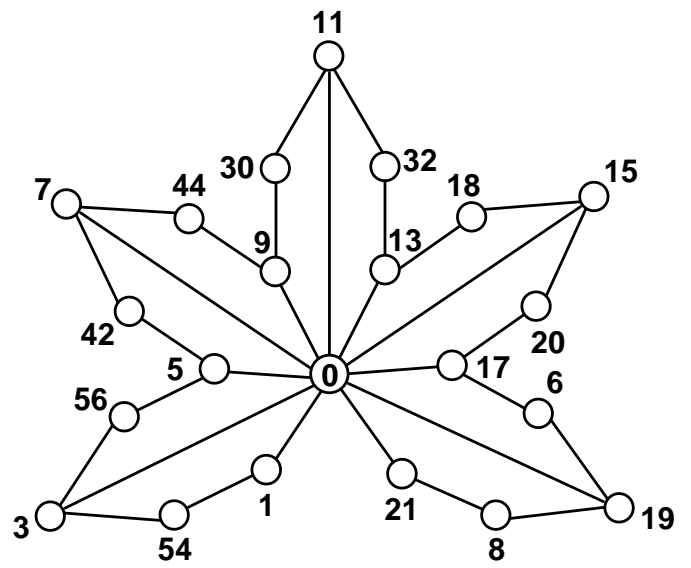

Gambar 2. Pelabelan harmonis ganjil pada graf $F D Q(5)$

Contoh 4. Pelabelan harmonis ganjil pada graf $F D Q(6)$

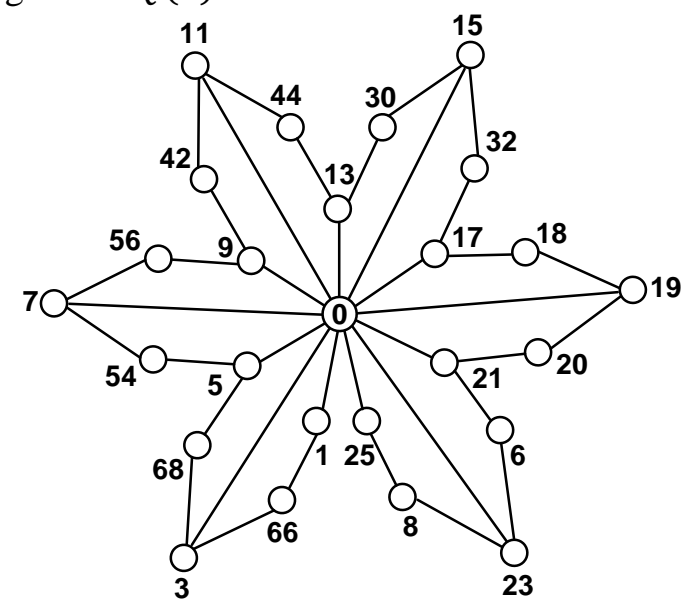

Gambar 3. Pelabelan harmonis ganjil pada graf $F D Q(6)$

Definisi 5. Graf bunga variasi double quadrilteral $F V D Q(m)$ dengan $m \geq 1$ adalah graf yang mempunyai himpunan titik $V(F V D Q(m))=\left\{u_{0}\right\} \cup$ $\left\{u_{i} \mid 1 \leq i \leq 2 m+1\right\} \cup$ $\left\{v_{i}^{j} \mid 1 \leq i \leq m, j=1,2\right\} \cup$ $\left\{w_{i} \mid 1 \leq i \leq 2 m\right\} \cup\left\{x_{i} \mid 1 \leq i \leq m\right\} \quad$ dan himpunan garis $E(F V D Q(m))=$ $\left\{u_{0} u_{i} \mid 1 \leq i \leq 2 m+1\right\} \cup$ $\left\{u_{2 i-1} v_{i}^{1} \mid 1 \leq i \leq m,\right\} \cup$ 


$$
\begin{aligned}
& \left\{v_{i}^{j} u_{2 i} \mid 1 \leq i \leq m, j=1,2\right\} \cup \\
& \left\{u_{2 i+1} v_{i}^{2} \mid 1 \leq i \leq m,\right\} \cup \\
& \left\{u_{2 i-1} w_{2 i-1} \mid 1 \leq i \leq m\right\} \cup \\
& \left\{u_{2 i+1} w_{2 i} \mid 1 \leq i \leq m\right\} \cup \\
& \left\{w_{2 i-1} u_{2 i} \mid 1 \leq i \leq m\right\} \cup \\
& \left\{w_{2 i} u_{2 i} \mid 1 \leq i \leq m\right\} \cup \\
& \left\{v_{i}^{j} x_{i} \mid 1 \leq i \leq m, j=1,2\right\} .
\end{aligned}
$$

Berdasarkan Definisi 5 diperoleh order $p(F V D Q(m))=7 m+2 \quad$ dan size $q(F V D Q(m))=12 m+1$.

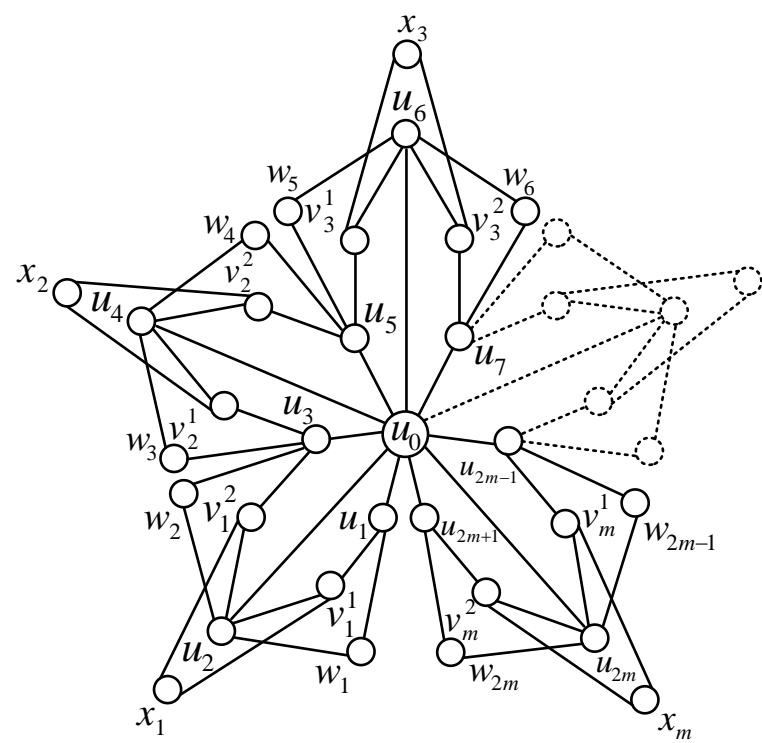

Gambar 4. Konstruksi dan definisi titik dari graf bunga variasi double quadrilateral $F V D Q(m)$ dengan $m \geq 1$.

Teorema 6. Graf bunga variasi double quadrilteral $F V D Q(m)$ dengan $m \geq 1$ adalah graf harmonis ganjil.

Bukti.

Didefinisikan fungsi pelabelan titik $f: V(F V D Q(m)) \rightarrow\{0,1,2,3, \ldots, 24 m+1\}$

$f\left(u_{0}\right)=0$

$f\left(u_{i}\right)=2 i-1,1 \leq i \leq 2 m+1$

$f\left(v_{i}^{j}\right)=12 m-12 i+2 j+4$,

$$
1 \leq i \leq m, j=1,2
$$

$f\left(w_{i}\right)=12 m+2 i, 1 \leq i \leq 2 m$

$f\left(x_{i}\right)=8 m+16 i-7,1 \leq i \leq m$

Berdasarkan persamaan (8), (9), (10), (11) dan (12) diperoleh

$f(V(F V D Q(m)))=\{0\} \cup$

$\{1,3,5,7, \ldots, 4 m+1\} \cup\{12 m-6,12 m-$ $18,12 m-30,12 m-42, \ldots, 6,12 m-$
$4,12 m-16,12 m-28,12 m-40, \ldots, 8\} \cup$ $\{12 m+2,12 m+4,12 m+6,12 m+$ $8, \ldots, 16 m\} \cup\{8 m+9,8 m+25,8 m+$ $41,8 m+57, \ldots, 24 m-7\}$

$=\{0,1,3,5,6,7,8, \ldots, 4 m+1,8 m+9,8 m+$ $25,8 m+41,8 m+57, \ldots, 12 m-42,12 m-$ $40,12 m-30,12 m-28,12 m-18,12 m-$ $16,12 m-6,12 m-4,12 m+2,12 m+$ $4,12 m+6,12 m+8, \ldots, 16 m, \ldots, 24 m-7\}$ $=\{0,1,3,5, \ldots, 24 m-7\}$

Didapatkan himpunan titik setelah diberikan label $f(V(F V D Q(m)))=$ $\{0,1,3,5, \ldots, 24 m-7\} \subseteq\{0,1,2,3, \ldots, 24 m+$ 1\}. Disisi yang lain terlihat juga bahwa himpunan titik setelah diberi label $f(V(F V D Q(m)))=\{0,1,3,5, \ldots, 24 m-7\}$ menghasilkan label yang berbeda-beda pada setiap titiknya. Sehingga didapatkan fungsi pelabelan titik bersifat injektif.

Didefinisikan fungsi pelabelan garis $f^{*}: E(F V D Q(m)) \rightarrow\{1,3,5,7, \ldots, 24 m+1\}$

$f^{*}\left(u_{0} u_{i}\right)=2 i-1,1 \leq i \leq 2 m+1$

$f^{*}\left(u_{2 i-1} v_{i}^{1}\right)=12 m-8 i+2 j+1$,

$1 \leq i \leq m$,

$f^{*}\left(v_{i}^{j} u_{2 i}\right)=12 m-8 i+2 j+3$,

$1 \leq i \leq m, j=1,2$

$f^{*}\left(u_{2 i+1} v_{i}^{2}\right)=12 m-8 i+2 j+5$,

$1 \leq i \leq m$,

$f^{*}\left(u_{2 i-1} w_{2 i-1}\right)=12 m+8 i-5$,

$1 \leq i \leq m$,

$f^{*}\left(u_{2 i+1} w_{2 i}\right)=12 m+8 i+1$,

$1 \leq i \leq m$,

$f^{*}\left(w_{2 i-1} u_{2 i}\right)=12 m+8 i-3$,

$1 \leq i \leq m$,

$f^{*}\left(w_{2 i} u_{2 i}\right)=12 m+8 i-1$,

$1 \leq i \leq m$,

$f^{*}\left(v_{i}^{j} x_{i}\right)=20 m+4 i+2 j-3$,

$1 \leq i \leq m, j=1,2$

Berdasarkan persamaan (13), (14), (15), (16), (17), (18), (19), (20), dan (21) diperoleh $f^{*}(E(V F D Q(m)))=\{1,3,5,7, \ldots, 4 m+$ 1\} $\cup\{12 m-5,12 m-13,12 m-21,12 m-$ $29, \ldots, 4 m+3\} \cup\{12 m-3,12 m-$ $11,12 m-19,12 m-27, \ldots, 4 m+5,12 m-$ $1,12 m-9,12 m-17,12 m-25, \ldots, 4 m+$ 7\} $\cup\{12 m+1,12 m-7,12 m-15,12 m-$ 
$23, \ldots, 4 m+9\} \cup\{12 m+3,12 m+$ $11,12 m+19,12 m+27, \ldots, 20 m-5\} \cup$ $\{12 m+9,12 m+17,12 m+25, \ldots, 20 m+$ 1) $\cup\{12 m+5,12 m+13,12 m+21,12 m+$ $29, \ldots, 20 m-3\} \cup\{12 m+7,12 m+$ $15,12 m+23,12 m+31, \ldots, 20 m-1\} \cup$ $\{20 m+3,20 m+7,20 m+11,20 m+$ $15, \ldots, 24 m-1,20 m+5,20 m+9,20 m+$ $13,20 m+17, \ldots, 24 m+1\}$

$=\{1,3,5,7, \ldots, 4 m+1\} \cup\{4 m+3,4 m+$ $5,4 m+7,4 m+9, \ldots, 12 m-29,12 m-$ $27,12 m-25,12 m-23,12 m-21,12 m-$ $19,12 m-17,12 m-15,12 m-13,12 m-$ $11,12 m-9,12 m-7,12 m-5,12 m-$ $3,12 m-1,12 m+1\} \cup\{12 m+3,12 m+$ $5,12 m+7,12 m+9,12 m+11,12 m+$ $13,12 m+15,12 m+17,12 m+19,12 m+$ $21,12 m+23,12 m+25,12 m+27,12 m+$ $29,12 m+31, \ldots, 20 m-5,20 m-3,20 m-$ $1,20 m+1\} \cup\{20 m+3,20 m+5,20 m+$ $7,20 m+9,20 m+11,20 m+13,20 m+$ $15,20 m+17, \ldots, 24 m-1,24 m+1\}$ $=\{1,3,5,7, \ldots, 4 m+1,4 m+3,4 m+5,4 m+$ $7,4 m+9, \ldots, 12 m-29,12 m-27,12 m-$ $25,12 m-23,12 m-21,12 m-19,12 m-$ $17,12 m-15,12 m-13,12 m-11,12 m-$ $9,12 m-7,12 m-5,12 m-3,12 m-$ $1,12 m+1,12 m+3,12 m+5,12 m+$ $7,12 m+9,12 m+11,12 m+13,12 m+$ $15,12 m+17,12 m+19,12 m+21,12 m+$ $23,12 m+25,12 m+27,12 m+29,12 m+$ $31, \ldots, 20 m-5,20 m-3,20 m-1,20 m+$ $1,20 m+3,20 m+5,20 m+7,20 m+$ $9,20 m+11,20 m+13,20 m+15,20 m+$ $17, \ldots, 24 m-1,24 m+1\}$

$=\{1,3,5,7, \ldots, 24 m+1\}$

Didapatkan himpunan garis setelah diberikan label $f^{*}: E(F V D Q(m))=$ $\{1,3,5,7, \ldots, 24 m+1\}$. Disisi yang lain terlihat juga bahwa himpunan garis setelah diberi label $f^{*}: E(F V D Q(m))=\{1,3,5,7, \ldots, 24 m+$ 1) menghasilkan label yang berbeda-beda pada setiap garisnya. Sehingga didapatkan fungsi pelabelan garis bersifat bijektif.

Sedemikian sehingga diperoleh graf bunga variasi double quadrilateral $F V D Q(m)$ dengan $m \geq 1$ adalah graf harmonis ganjil.
Contoh 7. Pelabelan harmonis ganjil pada graf FVDQ(5)

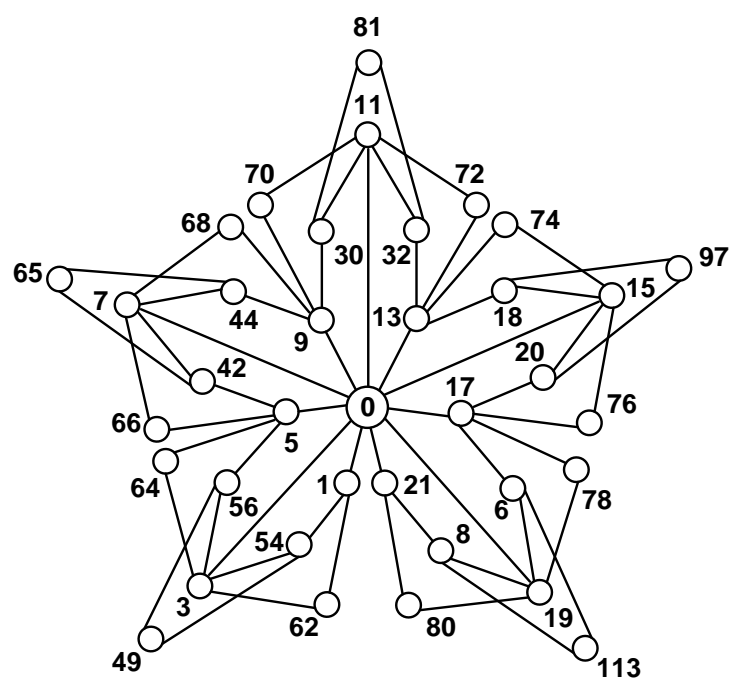

Gambar 5. Pelabelan harmonis ganjil pada graf FVDQ(5)

Contoh 8. Pelabelan harmonis ganjil pada graf $F V D Q(6)$

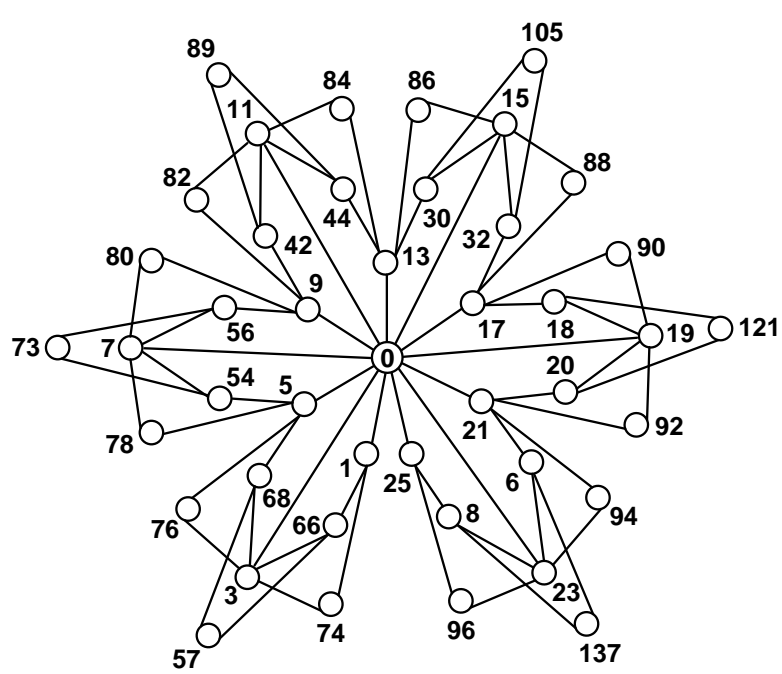

Gambar 6. Pelabelan harmonis ganjil pada graf FVDQ(6)

\section{KESIMPULAN}

Berdasarkan hasil dan pembahasan dapat ditarik kesimpulan bahwa graf bunga double qudrilateral $F D Q(m)$ dengan $m \geq 1$ adalah graf harmonis ganjil (Teorema 2). 
Selain itu juga telah dibuktikan bahwa graf bunga variasi double quadrilateral $F V D Q(m)$ dengan $m \geq 1$ adalah graf harmonis ganjil (Teorema 6).

\section{DAFTAR PUSTAKA}

Abdel-Aal, M. E. 2014. New Families of Odd Harmonious Graphs. International Journal of Soft Computing, Mathematics and Control, 3(1): 1-13.

Firmansah, F. 2017. The Odd Harmonious Labeling on Variation of the Quadrilateral Windmill Graphs. Jurnal Ilmu Dasar, 18(2): 109-118.

Firmansah, F. \& M.W. Syaifuddin. 2016. Pelabelan Harmonis Ganjil pada Graf Kincir Angin Double Quadrilateral. Magistra, 28(97): 71-77.

Firmansah, F. \& M.W. Syaifuddin. 2018. Pelabelan Harmonis Ganjil pada Amalgamasi Graf Kincir Angin Belanda. Fibonacci Jurnal Matematika dan Pendidikan Matematika, 4(4): $37-$ 46.

Firmansah, F. \& M.W. Syaifuddin. 2018a. Pelabelan Harmonis Ganjil pada Amalgamasi Graf Kincir Angin Double Qudrilateral. Seminar Nasional Pendidikan Matematika Ahmad Dahlan SENDIKMAD, 6: 59-64.

Firmansah, F. \& Tasari. 2020. Odd Harmonious Labeling on Edge Amalgamation from Double Quadrilateral Graphs. Desimal Jurnal Matematika, 3(1): 65-72.
Firmansah, F. \& M.R. Yuwono. 2017. Pelabelan Harmonis Ganjil pada Kelas Graf Baru Hasil Operasi Cartesian Product. Jurnal Matematika Mantik, 3(2): 87-95.

Firmansah, F. \& M.R. Yuwono. 2017a. Odd Harmonious Labeling on Pleated of the Dutch Windmill Graphs. Chaucy Jurnal Matematika Murni dan Aplikasi, 4(4): 161-166.

Gallian, J. A. 2019. Dynamic Survey of Graph Labeling. The Electronic Journal of Combinatorics, 18.

Jeyanthi, P. \& S. Philo. 2019. Odd Harmonious Labeling of Super Subdivision Graphs. Proyecciones Journal of Mathematics, 38(1): 1-11.

Liang, Z. \& Z. Bai. 2009. On The Odd Harmonious Graphs with Application. J. Appl. Math. Comput, 29:105-116.

Rismayati. 2013. Pelabelan Harmonis Ganjil pada Graf Hairy Cycle, Graf Shadow Lingkaran dan Graf Generalisasi Shadow Lingkaran. [Tesis]. Departemen Matematika FMIPA Universitas Indonesia. 